\title{
Connecting Hazard Analysts and Risk Managers to Sensor Information
}

\author{
Gonéri Le Cozannet ${ }^{1}{ }^{*}$, Steven Hosford ${ }^{2}$, John Douglas ${ }^{1}$, Jean-Jacques Serrano ${ }^{1}$, \\ Damien Coraboeuf ${ }^{1}$ and Jérémie Comte ${ }^{1}$
}

1 BRGM - French Geological Survey, 3 avenue Claude Guillemin, 45060 Orléans, France; E-mails: j.douglas@brgm.fr (J.D.); jj.serrano@brgm.fr (J.-J.S.); dcoraboeuf@yahoo.fr (D.C.); j.comte@brgm.fr (J.C.)

2 CNES, 18, avenue Edouard Belin, 31401 Toulouse cedex 9, France;

E-Mail: steven.hosford@cnes.fr (S.H.)

* Author to whom correspondence should be addressed; E-mail: g.lecozannet@ brgm.fr (G.C.)

Received: 23 April 2008; in revised form: 6 June 2008 / Accepted: 9 June 2008 /

Published: 11 June 2008

\begin{abstract}
Hazard analysts and risk managers of natural perils, such as earthquakes, landslides and floods, need to access information from sensor networks surveying their regions of interest. However, currently information about these networks is difficult to obtain and is available in varying formats, thereby restricting accesses and consequently possibly leading to decision-making based on limited information. As a response to this issue, state-of-the-art interoperable catalogues are being currently developed within the framework of the Group on Earth Observations (GEO) workplan. This article provides an overview of the prototype catalogue that was developed to improve access to information about the sensor networks surveying geological hazards (geohazards), such as earthquakes, landslides and volcanoes.
\end{abstract}

Keywords: hazard maps, geohazards, OGC metadata catalogue, risk management, GEOSS.

\section{Introduction}

Attempts to catalogue sensor data lead to gathering heterogeneous information, which makes the architecture of such catalogues difficult to manage. This is because scientists and engineers concerned with geological hazards, such as earthquakes, landslides and volcanoes (here grouped under the collective term geohazards), use heterogeneous in-situ and remote sensing data and modelling tools to 
produce information for decision makers. Hazard maps are one of the final products that land-use planners need during the planning and development of new buildings and infrastructure. In order to produce hazard maps, scientists need various sensor data from varied sources including geological maps, databases of historical events, digital elevation models, as well as land-cover maps. This information can be derived from data produced by many types of sensors, such as high-resolution space or airborne imagery, hyper-spectral data, borehole data, seismometer data, GPS networks and other geophysical in-situ and space instrumentation. While it is very challenging to produce a metadata system gathering all data available for hazard mapping, another approach, which consists of collecting the existing hazard maps and their underlying data, is proposed here.

\section{International framework}

The design of a Global Earth Observing System of Systems (GEOSS) to respond to society's needs for information on the earth environment has been the concern of GEO, the Group on Earth Observations (http://www.earthobservations.org/), since its inception as an ad hoc group in July 2003. One of the key challenges of GEOSS is its architecture. The users of GEOSS will expect to use a flexible system, enabling search, retrieval and archiving of accessible datasets through a distributed network of servers. In order to achieve this goal, interoperability arrangements amongst data providers are necessary. This implies widespread adoption of state-of-the-art interoperability standards.

GEO's "Geohazards Community of Practice" (CoP, http://www.igosgeohazards.org/), is an international partnership of space agencies, geological surveys and scientific organisations that are concerned with improving access to geospatial data and information for the mitigation, prevention and monitoring of geophysical hazards. This community undertook, under GEO, to design and develop an interoperable and distributed metadata system applied to the inventory of hazard maps. This system has been named GeoHazData.

\section{GeoHazData concept}

During the 2006-2007 period, the GEO Geohazards CoP was used to collect user requirements. Then, a metadata editor and a web map service were produced, and finally, strategies to perform the actual inventory were tested.

\section{User requirements}

GeoHazData takes as its starting point an end user need: the requirement to access geohazard maps for a region. The requirement of decision makers for hazard evaluation is common to all geohazards. Hazard is commonly characterised in terms of the probability of a measurable physical parameter (or, occasionally, parameters) exceeding a certain threshold during a period of time. For example, the conference proceedings edited by Vecchia [1] shows that this is a common approach for many natural hazards. In addition, Douglas [2] shows that there are many common requirements and procedures for the development and presentation of such hazard (and, when hazard is combined with a consideration of vulnerability, risk) maps. However, even though the overall goal of most geohazard assessments is similar, the methods for their production and the data used are generally peril-specific. 
The analysis of the needs of potential users of GeoHazData was performed in order to produce a metadata system able to describe the hazards maps in a homogeneous way [4]. During the $2^{\text {nd }}$ International Geohazards Workshop held at BRGM in Orléans (France) in June 2005, a working group of scientists and experts concerned with integration of data to produce seamless information for decision makers was set up, with the aim of identifying the data used to produce information products such as hazard maps. This working group produced a preliminary user requirement document, which was reviewed and completed by a survey launched in early 2006. This user requirement process allowed the identification of the required fields and definitions of the hazard map inventory system. Figure 1 gives an overview of the overall concept of the GeoHazData hazard map inventory tool. It includes the following components.

\section{GeoHazData Architecture}

Figure 1. Overall concept of the GeoHazData hazard map inventory tool. The metadata editor generates ISO 19115-compatible metadata registered in an Open Geospatial Consortium (OGC, http://www.opengeospatial.org/) catalogue [5]. This catalogue is stored on a publicly accessible server. The acquired data can be shared using a dedicated server, published on any other OGC compliant catalogue or exported locally in XML format. A Web Map Service (WMS) enables viewing the extent and content of the metadata. Finally, this catalogue can be interrogated by any other OGC client application.






\section{Catalogue content}

The user requirements process showed that the critical parameters for the characterization of hazard maps are the following.

- Fundamental data: pertaining to the characteristics of the map itself (e.g. coverage, scale, date of production, creator and publishing organisation). These are "standard" data fields that are relevant to many geospatial datasets and are already provided for in geospatial metadata standards.

- Information providing an indication of the quality of the map including how and why this map was generated and the data and methods used.

One of the important user requirements was to enable GeoHazData users to access information on the source data, i.e. to the data layers as well as to the processes used to produce this hazard map. This helps the user understand the "reliability" of the hazard evaluation and gives an indication of how the hazard map should be used. This is characterized by:

- The sources: the user requirements process defined a set of "interpreted data layers" for each of the geohazards that are typically required for evaluating hazard. These interpreted data layers are listed in Table 1. For each of these interpreted data layers a certain number of measured data layers have been identified.

- The process: that allowed the production of the hazard maps. The process is often a clearly defined process, such as modelling tools used to map the hazard complemented by advice from geologists.

- Legal constraints on access and use applied to the hazard map itself or of the underlying data.

\section{Interoperability features}

In order to be a useful contribution to GEOSS, GeoHazData must be interoperable with other catalogues contributing to GEOSS. As an OGC catalogue of ISO 19115 metadata GeoHazData uses state-of-the-art interoperability standards and is, therefore, interoperable with other OGC catalogues and clients. This follows the recommendations of the GEO Data and Architecture Committee. The interoperability features of GeoHazData were successfully tested during a demonstration of the GEOSS Clearing House at GEO III (Bonn) in November 2005. This demonstration showed however that clients require some specific adjustments to be able to access in an interoperable way catalogues based on various profiles.

\section{Lessons learnt and conclusion}

The GeoHazData hazard map inventory tool was intended as a contribution to the implementation of GEOSS. In order to test this concept, some metadata were added to the server using the metadata editor. These metadata mostly come from previous hazard surveys performed by BRGM.

The most critical issue for the actual implementation of the GEOSS Geohazards component is to find a cooperation scheme under which the members actually commit to insert content in the database. GEO and its Geohazards CoP were identified as the appropriate frameworks. Our approach was to 
propose the GeoHazData concept to GEO Member states in order to launch the implementation process. GEO member states and participating organisations are invited to critically review the GeoHazData hazard map inventory tool.

Table 1. List of sources useful for the creation of hazard maps. These sources allow the user to identify the data available for the region of interest. Volcanic hazards correspond to all hazards known in the area of interest. These can be (non-exhaustive list): lava flows, ash fall, gas emissions, lahars, ground movements, tidal waves or hydrothermal explosion. Volcanic hazard maps either show the estimated probability of occurrence of one of these hazards only, or a combination of all these hazards. As an example, a volcanic multi-risk approach has been described in Thierry et al., 2007 [3].

\begin{tabular}{|c|c|c|}
\hline Seismic hazard & instability & Volcanic hazards \\
\hline Instrumental seismicity catalogue & Geological characterisation & Volcanological structure \\
\hline Amplification spectrum & Geotechnical characterisation & Geological characterisation \\
\hline Crustal deformation in region & Hydrogeological characterisation & Geomorphological \\
\hline Active fault catalogue & Geomorphological characterisation & characterisation \\
\hline Model of crustal velocity structure & Topographic surface & Geotechnical characterisation \\
\hline A posteriori liquefaction occurrence & Deformation monitoring & Hydrogeological characterisation \\
\hline during earthquake & & Gas information \\
\hline Liquefaction susceptibility & & Historical events database \\
\hline Earthquake forecast maps & & Deformation monitoring \\
\hline Digital elevation model (site effects) & & Geochemical monitoring \\
\hline & & Seismic monitoring \\
\hline
\end{tabular}

\section{Acknowledgements}

This project was co-funded by the European Space Agency (ESA) and BRGM (the French Geological Survey).

\section{References and Notes}

1. Vecchia, V. A unified approach to probabilistic risk assessments for earthquakes, floods, landslides, and volcanoes. In Proceedings of a multidiscipilinary workshop held in Golden, Colorado November 16-17 1999, Open-File Report 01-324, U.S. Geological Survey; 2001.

2. Douglas, J. Methods and tools for risk evaluation, RISK-NAT. Module 4. Progress report. RP54041-FR, BRGM, Orléans, France; 2005.

3. Thierry, P.; Stieltjes, L.; Kouokam, E.; Nguéya, P.; Salley, P.M. Multi-hazard risk mapping and assessment on an active volcano: the GRINP project at Mount Cameroon. Natural Hazards 2008, 45, 429-456; DOI 10.1007/s11069-007-9177-3.

4. Hosford, S.; Le Cozannet, G. IGOS Geohazards Mid-Term Report. BRGM/RP-54827-FR, 2006. 
5. Le Cozannet, G.; Hosford, S.; Coraboeuf, D.; Salichon, J. Metadata Editor User Guide, Final Report, BRGM/RP-54937-FR, 2006.

(C) 2008 by the authors; licensee Molecular Diversity Preservation International, Basel, Switzerland. This article is an open-access article distributed under the terms and conditions of the Creative Commons Attribution license (http://creativecommons.org/licenses/by/3.0/). 